\title{
Desirable Status of the Dental Curriculum Based on the National Requirements of Iran and International Experiences
}

\author{
Maryam Safarnavadeh ${ }^{(i D)}$, Samira Ebrahimpour komeleh ${ }^{2}$, Soudeh Jafari $^{3^{*}}$ (iD) \\ ${ }^{1}$ Member of Academic Board of Education Department Ministry of Health, Treatment and Training, Secretariat of Technical and \\ Dentistry Training Council ,Tehran, Iran. \\ ${ }^{2}$ Department of Educational Science, Science and Research Branch, Islamic Azad University, Tehran, Iran. \\ ${ }^{3}$ Department of Oral Medicine, School of Dentistry, Shahid Beheshti University of Medical Sciences, Tehran, Iran.
}

Article Info

\section{Article Type:}

Original Article

\section{Article history:}

Received 21 May 2018

Accepted 22 Dec 2018

Published 19 March 2019

\section{Keywords:}

Curriculum

Dentistry

Integrated Curriculum

International Experiences

\begin{abstract}
Background $\boldsymbol{\&}$ Objective: Dentistry is one of the branches of medical sciences, which should change in response to the needs of the community in the third millennium. The present study aimed to determine the desirable status of the dental curriculum based on the domestic requirements of Iran and international experiences.

Materials and Methods: This was a qualitative, historical research. Using library studies and the analysis and interpretation of the obtained data, the dental curriculum and actual experiences of reputable universities were examined in Iran and some other countries. Following that, based on the theoretical arguments and empirical achievements of some reputable universities, the favorable status of the dental curriculum was investigated considering the domestic needs of Iran and international experiences.

Results: Through evaluation of the experiences of various universities in Iran and other universities across the world regarding the reform of the dental curriculum, it was concluded that the lack of a holistic approach, insufficient attention to the preventative aspects, separation of basic sciences education from clinical courses, lack of learning motivation in learners, and poor training of independent learners have urged the thorough review of the dental curriculum. The horizontal and vertical integration of the dental curriculum could enhance the current status of dentistry. Therefore, curriculum modification and reform should be focused on integrated approaches based on education combined with research, evidence-based dentistry, and introduction of new knowledge in the planning of the dental curriculum.

Conclusion: A favorable integrated curriculum for dental education is a program that develops the dental curriculum based on the academic field level, field of study level, and thematic program or course content level through deciding on the four elements of objectives, contents, methodology, and evaluation, as well as adherence to the four principles of simultaneous integration at the micro and macro levels, diversity of methods and multi-dimensionality, balance between the contents, and supplemented integration from within.
\end{abstract}

'Corresponding author: Soudeh Jafari, Email: drjafari@sbmu.ac.ir

This article is referenced as follows: Safarnavadeh M, Ebrahimpour Koumleh S, Jafari S. Desirable Status of the Dental Curriculum Based on the National Requirements of Iran and International Experiences. $\mathrm{J}$ Med Educ Dev. 2019; 11 (32):99-125 


\section{Introduction}

Dentistry is one of the branches of medical sciences, which requires modifications in the context of routine educational changes in the world in order to meet the needs of communities in the third millennium (1). This is due to the fact that many dentistry students, have an improper understanding of the association of the basic sciences they have been trained on and the knowledge required to establish a link between research and practice even after receiving the official documents upon graduation. Therefore, the general dental course curriculum requires contents that meet the needs of the modern world (2-4).

Despite the approach governing the dental education, which involves the separation of basic sciences from clinical sciences, success in the practical curriculum of dentistry requires the coordination and integration of the theoretical education and practical training (5). In this regard, the American Dental Association (ADA) has emphasized on attention to modern data transfer techniques, as well as the progress of e-tools, studentoriented methods and clinical stimuli, combination of medicine and pathology, and behavioral and social sciences as important issues in dental education (1). Therefore, the integrated dental curriculum is one of the most practical approaches to addressing the needs of dentistry in the $21^{\text {st }}$ century.

Curriculum integration is defined as connecting and interlacing the contents of educational syllabi in order to integrate the learning experiences of students (6). The integrated curriculum model includes the viewpoints and guidelines presented by experts in medical education and curriculum planning for the optimal organization of the contents of the integrated curriculum $(7,8)$.

Integration into medical education is classified as horizontal and vertical, with the former aiming to integrate the courses that are taught in one stage; such example is the integration of basic sciences (e.g., embryology, histology, and pathology) and clinical courses (e.g., preventative medicine, psychiatry, and geriatrics). In fact, such integration involves the courses that are presented in one stage, and the time of their presentation is considered as a unit in terms of implementation $(9,10)$.

Vertical integration aims to integrate the courses that are learned in a timely manner. Vertical integration between basic and clinical sciences using problem-based learning could extend the learning process. In fact, vertical integration involves the early contact of students with patients in the first semesters in 
terms of basic sciences, as well as basic sciences education in the clinical course curriculum (11).

In dental schools such as Harvard, Virginia, Marquette, Baylor, Boston, and Columbia, dental curriculum integration has been considered in order to implement reforms in the general dentistry curriculum. For instance, the dental course at Harvard University is a four-year course that leads to a degree in general dentistry. The course topics include lectures with multidisciplinary courses and group discussions, laboratory projects, and independent studies. The main approaches in this regard are problem-based, learning through discussions in small groups, and analyzing the cases of actual patients in order to encourage students to take on their own learning responsibilities and develop continuous learning skills.

To contribute to the integration of medical and dental sciences within the past two years, parallel dentistry courses have been provided to allow students to communicate between oral health and whole body health. For instance, while passing the block of the human body, students are trained on craniofacial anatomy and identification of the anatomical structures in radiology images. During the third year of studying doctor/patient courses, students learn interpersonal communications and role of the community and environment in patient care. Furthermore, they are trained on data collection skills from the patient and physical examinations. Some practical courses are also provided in combination in order to become acquainted with the practical aspects of patient care, including the individuals and institutions that are in interaction with dentists. The exam and assessment system and review and feedback are fully designed to allow students to become acquainted with the offered courses (12).

The School of Dentistry at the West Virginia University launched a general review of its curriculum in 2002, thereby becoming the first department to start with the new, redefined dentistry curriculum in 2006. The objectives of the revised curriculum include the provision of educational contents for the courses that are complete and comprehensive and contain the common contents that students must learn, while free of additional, repetitive, and redundant contents.

Integration of theoretical courses and practical lessons to enhance learning realization and implementation of this major principle in the curriculum of dentistry schools, so that students could learn and apply the clinical 
care and public services required by patients at the earliest possible opportunity and become empowered in terms of the tasks that are appropriate to the practical knowledge and experience of dentistry. This process could cause the acquisition of the necessary abilities for dentists. Furthermore, it helps them to properly address the needs of the patients based on the teamwork approach in dentistry. In the present study, changes in the curriculum occurred at levels, beginning with modifications in the basics courses. The contents of the basic courses and sequences of their presentation were modified as well. A subcommittee was set up to accelerate the integration of theoretical and applied courses, and another subcommittee was assembled for behavioral sciences and clinical sciences with the same objective, which was to accelerate the integration of behavioral sciences into clinical sciences. Moreover, a thorough analysis was performed on the contents and sequences of the previous curriculum subjects, and the additional, modified, and eliminated courses were reviewed and approved by the educational council of the college and university. The current preclinical program has also changed, and new introductory lessons have been added to the curriculum with the subjects of preventative dentistry, community dentistry, and patient care, so that the junior and sophomore students would experience the pre-designed learning and practical integration of the theoretical and practical courses in a timely manner. Via this approach, students enter the clinic one year earlier than the previous curriculum (i.e., during the second year).

The integration of simulated computer patient into the curriculum of dentistry has made students feel at ease with new issues and innovations, while enjoying the opportunity to engage in earlier encounters with patients in this program. In general, the efficiency of students in the clinic has been reported to be noticeably high due to their early entry into the clinic (13).

In March 1999, the Marquette University began rebuilding its curriculum. Over a period of eight years, these changes occurred in two phases (phase I and II); in the first phase, the elimination of lessons from the history, reduced use of traditional methods (e.g., lectures), integration of basic, behavioral, and clinical sciences into four years of dental education, implementation of cased-based rounds, early contact with the clinical environment, and development and strengthening of interpersonal and patient communication skills were considered. 
The second phase was accomplished through the introduction of new sciences, researchdriven students, and conducting academic research by applying new sciences and biomedicine in the clinic for the advancement of patient care. The curriculum used at Marquette University includes statistics and research methodology, advanced computer courses, use of effective teaching methods, advanced research, molecular medicine, professional and research ethics, research in education, use of the latest science and technology in patient care, use of electronic science resources, student self-assessment, and evaluation based on objective structured clinical examination (14).

The presentation of the dental course at Baylor University indicated that the university previously used a numerical scoring system in order to evaluate the daily performance of students in the clinic. When the curriculum was converted into a comprehensive, clinical, competency-based approach, the evaluation method also changed and replaced by a qualitative (non-numerical) approach. The qualitative scoring system resulted in improved learning and interactivity of the educators, increased workload in the clinic with less stress, and proposing more suggestions by professors regarding the correction of the practical projects presented to the students (15).

Evaluation of the provided dentistry courses in an integrated dental curriculum at the College of Dentistry at the University of Boston and Colombia has two main components, including the integration of community-based education (community education) into the dentistry curriculum and close attention to the network of dental services $(16,17)$.

A general overview of the current pattern of the dental curriculum in Iran and its other governing features (e.g., separation of basic sciences from each other and from the clinical sciences and disregarding the horizontal and vertical linkage between the topics) suggests that the principles of the integrated curriculum have not been properly addressed in this program.

Considering the effects and consequences of integration into the dental curriculum (9), it is essential to adopt appropriate approaches in dental curriculum in accordance with the ecosystem of Iran in order to update the curriculum. The present study aimed to illustrate the desirable status of the dental curriculum through investigating the domestic requirements of Iran and examining the experiences of the leading universities across 
the world in applying integrated approaches for dental curricula. Applying international dentistry curricula to Iran has some benefits, including the provision of appropriate opportunities for the immediate establishment of commination between dentistry students and patients and integration of basic sciences education for dentistry and medical students.

Using the experiences of international universities in the revision of their dental curriculum and modification of the dental curriculum in Iran based on the findings could lead to desirable outcomes, such as providing appropriate opportunities for the immediate establishment of communication between dentistry students and patients and integrating basic sciences education for dentistry and medical students.

The present study aimed to investigate the desired status of the dental curriculum based on the domestic needs of Iran and international experiences.

\section{Materials and Methods}

This historical research was conducted using a qualitative approach to assess the integration of the dental curriculum from an analytical perspective using available resources and documents. Historical research examines specific issues at a specific time, and the researcher evaluates the integrity of the material to interpret and analyze the obtained information. Given the theoretical nature of the current research, data were collected by taking notes through the study of the documents. For this purpose, the current literature regarding integrated curricula was reviewed, and the relevant documents were used to collect the data on the general dental curriculum in Iran and other reputable universities in the world.

This review was limited to a specific time frame in order to examine the status of Iran during the period covering the current program and international universities since 2000 as the most recent examples in this regard. In order to access the required resources, in addition to referring to the prestigious universities in Iran, including the School of Dentistry at Shahid Beheshti University of Medical Sciences (Tehran, Iran), School of Dentistry at Tehran University of Medical Sciences (Tehran, Iran), School of Dentistry at Islamic Azad University, Shahed University, and the medical universities in Kerman, Isfahan, and Tabriz, the scientific and research documents were reviewed using the spider's web method. In this method, each source provides the clues from other sources, leading the research to 
new information. The spider's web method is particularly applied to obtain information on the sources outside of Iran.

In the present study, a targeted, organized search was performed to collect the required data. To access a wide range of scientific texts, the Google Scholar and Alta Vista search engines were used. Furthermore, literature search was performed in medical databases, such as PubMed and Medline, and to access bibliographies, databases such as ERIC and RDRB were applied using various keywords, including integration, integrative curriculum, dental school, dental curriculum, higher education, basics and elements of dentistry syllabus, and types of integration in order to find the theoretical literature and research backgrounds since 2000 .

On the other hand, we utilized methodologies such as document analysis, comparative study, and review of documentation. In general, the initial information plan in these methods was compiled based on the main research questions and sought in the relevant resources.

Data analysis was performed based on theoretical analysis focused on a questionnaire, and the obtained data were combined to form a comprehensive, logical answer. It is notable that their defensible organization was considered to be the basis for determining the validity of the applied method.

\section{Results}

Through reviewing the course of the changes in the dental curriculum in Shahid Beheshti University and Mashhad Dental School in Iran, as well as the universities in North America, Europe, Asia, and Australia (especially Marquette, Texas, and Connecticut universities), which introduced some modifications to the dental curriculum and had some experiences in the integration of the dental curriculum $(18,19)$, it was concluded that vertical integration was more commonly used compared to horizontal integration during the first decade of the $21^{\text {st }}$ century. According to the obtained results, the common types of horizontal integration were applied in two cases, including the integration of basic sciences, behavioral sciences, and clinical sciences during the four years of dental education and integration of basic sciences with the topics relating to dentistry. On the other hand, the most common types of vertical integration were used in 40 cases, which are presented in Table 1. As providing the details of all the integration types was not possible in the present study, only a few 
measures have been mentioned based on the

by the final results of the study.

performance of some universities, followed

Table 1: Titles of Vertical Integration in Dental Curricula of Studied Universities

\begin{tabular}{|c|c|c|c|}
\hline No. & Title & No. & Title \\
\hline 1 & $\begin{array}{l}\text { Integration of basic sciences into clinical practice } \\
\text { and vice versa (e.g., early contact with patients) }\end{array}$ & 21 & $\begin{array}{l}\text { Basic pharmacology as a correlation between the } \\
\text { use of drugs in practical dentistry }\end{array}$ \\
\hline 2 & $\begin{array}{l}\text { Integration of dental diseases with general diseases } \\
\text { (i.e., integration of medical and surgical education } \\
\text { [human diseases] with the curricula of general } \\
\text { dentists and integration of medical and dental } \\
\text { sciences) }\end{array}$ & 22 & $\begin{array}{l}\text { Integration of microbiology courses with } \\
\text { periodontal courses }\end{array}$ \\
\hline 3 & $\begin{array}{l}\text { Integration of communication skills into all the } \\
\text { clinical dental skills (i.e., integration of sociology, } \\
\text { psychology, communication skills, education of } \\
\text { patient-dentist relations, determining the specific } \\
\text { needs, especially in oral medicine and dentistry) }\end{array}$ & 23 & Perio-restorative integration \\
\hline 4 & $\begin{array}{l}\text { Integration of new biomedical sciences, critical } \\
\text { thinking, and evidence-based skills into dentistry } \\
\text { subjects }\end{array}$ & 24 & $\begin{array}{l}\text { Integration of preventative dentistry and } \\
\text { pediatric dentistry courses }\end{array}$ \\
\hline 5 & $\begin{array}{l}\text { Integration of computer sciences and research } \\
\text { methodology into dentistry subjects }\end{array}$ & 25 & $\begin{array}{l}\text { Integration of the pediatric ward with the pre- } \\
\text { clinic restoration department }\end{array}$ \\
\hline 6 & $\begin{array}{l}\text { Integration of clinical dental sciences and } \\
\text { informatics, bioengineering, nanotechnology, and } \\
\text { molecular and biological sciences }\end{array}$ & 26 & $\begin{array}{l}\text { Integration of basic dental care with the } \\
\text { education of preventative issues of decays and } \\
\text { oral health for children and their families }\end{array}$ \\
\hline 7 & $\begin{array}{l}\text { Integration of basic sciences and clinical research } \\
\text { findings }\end{array}$ & 27 & $\begin{array}{l}\text { Integration of emergency pediatric dentistry } \\
\text { units }\end{array}$ \\
\hline 8 & $\begin{array}{l}\text { Integration of clinical sciences in comprehensive } \\
\text { clinics }\end{array}$ & 28 & $\begin{array}{l}\text { Integration of students' learning objectives with } \\
\text { clinical management and treatment }\end{array}$ \\
\hline 9 & $\begin{array}{l}\text { Integration of professional and proper ethics and } \\
\text { behaviors in dentistry subjects }\end{array}$ & 29 & $\begin{array}{l}\text { Integration of community-based education into } \\
\text { the dental curriculum }\end{array}$ \\
\hline 10 & $\begin{array}{l}\text { Integration of teamwork with oral health teams, } \\
\text { dentists, and dentistry nurses and management of } \\
\text { the team in all the dentistry subjects (management } \\
\text { and leadership of the oral health team) }\end{array}$ & 30 & $\begin{array}{l}\text { Integration of education through simulation in } \\
\text { dentistry }\end{array}$ \\
\hline
\end{tabular}




\section{Continue of Table 1: Titles of Vertical Integration in Dental Curricula of Studied Universities}

\begin{tabular}{llll}
\hline 11 & Integration of dentistry internship & 31 & $\begin{array}{l}\text { Integration of qualitative evaluation into the } \\
\text { dental evaluation curriculum }\end{array}$ \\
\hline 12 & $\begin{array}{l}\text { Integration of the education of professional and } \\
\text { ethical approaches in the routine dental education }\end{array}$ & 32 & Integration of emergencies into dentistry subjects \\
\hline & Integration of patient care into clinical education & 33 & $\begin{array}{l}\text { Integration of pain, anxiety, and trauma control } \\
\text { and management into the clinical subjects of } \\
\text { dentistry }\end{array}$ \\
\hline
\end{tabular}

Integration of theoretical and practical courses to

enhance the teaching and learning abilities of

14 students (theoretical courses are held as PBL-

Basic practical skills and geriatric dentistry

hybrid interdisciplinary and clinical courses as (dentistry in the elderly)

comprehensive patient care)

Vertical integration of system organs based on

15 basic medical sciences and clinical association of the subjects

Integration of biomedical, behavioral, and

clinical sciences into dentistry subjects

\begin{tabular}{|c|c|c|c|}
\hline 16 & $\begin{array}{l}\text { Integration of computer-simulated patients into the } \\
\text { curriculum }\end{array}$ & 36 & $\begin{array}{l}\text { Comprehensive clinic entry in dentistry clinical } \\
\text { courses }\end{array}$ \\
\hline 17 & $\begin{array}{l}\text { Integration of the restoration department (surgery, } \\
\text { mobile bearing, and fixed bearing prostheses) }\end{array}$ & 37 & $\begin{array}{l}\text { Integration of scenarios for the diagnosis and } \\
\text { treatment of new health problems into the } \\
\text { educational curriculum of dentistry }\end{array}$ \\
\hline 18 & $\begin{array}{l}\text { Content modifications in dental anatomy and } \\
\text { materials and taught as pre-clinical and in-clinic } \\
\text { subjects }\end{array}$ & 38 & $\begin{array}{l}\text { Integration of new sciences into all levels of } \\
\text { dental curriculum }\end{array}$ \\
\hline 19 & $\begin{array}{l}\text { Restoration department of physiology taught as } \\
\text { vertical integration with the theme of dental } \\
\text { curricula (levels one and two). }\end{array}$ & 39 & Integration of oral health with public health \\
\hline 20 & $\begin{array}{l}\text { Integration of oral diseases, oral surgery, and oral } \\
\text { pathology and diseases in close correlation with } \\
\text { mandibular surgery }\end{array}$ & 40 & $\begin{array}{l}\text { Integration of periodontal diseases with } \\
\text { polymorphism genetics, biomarkers, and cell } \\
\text { biology }\end{array}$ \\
\hline
\end{tabular}

Table 2 shows the global experiences in widely used in dentistry curricula. It is integrating various dental curricula considering that vertical integration is notable that the detailed report on each of the 40 commonly used vertical integrations in 
the dental colleges of the studied article, and only a few examples have been

universities has not been included in this presented.

Table 2: Global Experiences in Integration of Various Dentistry Curricula

\begin{tabular}{|c|c|c|c|c|}
\hline No & $\begin{array}{l}\text { Universities Using } \\
\text { Integrations }\end{array}$ & Topic of Integration & $\begin{array}{c}\text { Type of } \\
\text { Integration }\end{array}$ & $\begin{array}{c}\text { Compliance with Current } \\
\text { Status of Iran Regarding } \\
\text { Current Program Based on } \\
\text { Native Requirements }\end{array}$ \\
\hline 1 & $\begin{array}{l}\text { Marquette, Toronto, } \\
\text { UK, Texas }\end{array}$ & $\begin{array}{l}\text { Integration of basic sciences (horizontal } \\
\text { integration of the contents of basic } \\
\text { sciences in the form of body systems in } \\
\text { the dentistry curriculum, integration of } \\
\text { the contents of basic sciences in the form } \\
\text { of basic sciences education packages); } \\
\text { Example: For each organ, anatomy and } \\
\text { histology is provided. }\end{array}$ & Horizontal & $\begin{array}{c}\text { Courses requiring integration } \\
\text { incorporated into current } \\
\text { curriculum }\end{array}$ \\
\hline 2 & Harvard, Japan & $\begin{array}{l}\text { Integration of basic sciences with } \\
\text { clinical sciences (vertical integration of } \\
\text { clinical course contents in basic sciences } \\
\text { and vice versa) }\end{array}$ & Vertical & $*$ \\
\hline 3 & Baylor, Louisville & $\begin{array}{l}\text { Integration of oral hygiene with public } \\
\text { health and developing a unit known as } \\
\text { 'essential dental care' (dental care) }\end{array}$ & Vertical & $*$ \\
\hline 4 & Ankara, Sheffield & $\begin{array}{l}\text { Integration of pediatric dentistry } \\
\text { emergency into pediatric dentistry unit }\end{array}$ & Horizontal & $*$ \\
\hline 5 & Connecticut, USA & $\begin{array}{l}\text { Integration of preventative dentistry and } \\
\text { pediatric dentistry units }\end{array}$ & Horizontal & $*$ \\
\hline 6 & Germany, Netherlands & $\begin{array}{l}\text { Integration of microbiology courses with } \\
\text { periodontitis }\end{array}$ & Vertical & $*$ \\
\hline 7 & Pennsylvania, Toronto & $\begin{array}{l}\text { Vertical integration of system organs } \\
\text { based on basic medical sciences and } \\
\text { clinical communication of topics }\end{array}$ & Vertical & $*$ \\
\hline 8 & $\begin{array}{l}\text { Virginia, Harvard, } \\
\text { Boston, }\end{array}$ & $\begin{array}{l}\text { Integration of oral diseases, oral } \\
\text { pathology, and oral and maxillofacial } \\
\text { surgery }\end{array}$ & Horizontal & $*$ \\
\hline
\end{tabular}




\section{Continue of Table 2: Global Experiences in Integration of Various Dentistry Curricula}

\begin{tabular}{|c|c|c|c|c|}
\hline 9 & $\begin{array}{c}\text { Sweden, Switzerland, } \\
\text { Indonesia }\end{array}$ & $\begin{array}{l}\text { Integration of pre-clinical courses into } \\
\text { the department of pediatric dentistry } \\
\text { with the pre-clinical courses of } \\
\text { restoration and endodontics department }\end{array}$ & Vertical & $*$ \\
\hline 10 & Sydney, Pennsylvania & $\begin{array}{l}\text { Integration of research into dental } \\
\text { curriculum (research design and } \\
\text { advanced critical and applied statistics in } \\
\text { research) }\end{array}$ & Vertical & $\begin{array}{l}\text { Courses requiring revision with } \\
\text { integration view that are } \\
\text { available in current curriculum }\end{array}$ \\
\hline 11 & $\begin{array}{l}\text { England, Baylor, } \\
\text { Wales, Germany }\end{array}$ & $\begin{array}{l}\text { Integration of medical approaches into } \\
\text { clinical dental services (integrating } \\
\text { dental diseases with general diseases, } \\
\text { integrating medical and dental } \\
\text { education) }\end{array}$ & Vertical & $*$ \\
\hline 12 & $\begin{array}{l}\text { Connecticut, Canada } \\
\text { (Toronto), Virginia, } \\
\text { Marquette }\end{array}$ & $\begin{array}{l}\text { Integration of education on prevention } \\
\text { issues of various types of caries and oral } \\
\text { hygiene in children and their families }\end{array}$ & Vertical & $*$ \\
\hline 13 & New Jersey, Indiana & $\begin{array}{l}\text { Integration of professional ethics and } \\
\text { behaviors into dentistry (improving and } \\
\text { reviewing the topic of appropriate } \\
\text { professional and moral behaviors and } \\
\text { their integration throughout the six-year } \\
\text { period of dentistry education) }\end{array}$ & Vertical & $*$ \\
\hline 14 & $\begin{array}{l}\text { England, Baylor, } \\
\text { Wales, Germany }\end{array}$ & $\begin{array}{l}\text { Integration (introduction) and } \\
\text { application of sciences into dentistry } \\
\text { rounds based on diseases in the } \\
\text { curriculum (integration throughout the } \\
\text { six-year period of dentistry education) }\end{array}$ & Vertical & $\begin{array}{l}\text { Introduction of required and } \\
\text { new courses to complete } \\
\text { current curriculum }\end{array}$ \\
\hline 15 & $\begin{array}{l}\text { Netherlands, Belgium, } \\
\text { Sweden, Switzerland, } \\
\text { Dundee }\end{array}$ & $\begin{array}{l}\text { Integration (introduction) of medical } \\
\text { emergencies in the dentistry curriculum } \\
\text { (addition of emergency medicine } \\
\text { courses, recovering injuries, and first- } \\
\text { aid, and their integration throughout the } \\
\text { six-year period of dentistry education) }\end{array}$ & Vertical & $*$ \\
\hline
\end{tabular}




\section{Continue of Table 2: Global Experiences in Integration of Various Dentistry Curricula}

\begin{tabular}{|c|c|c|c|c|}
\hline 16 & $\begin{array}{c}\text { Austria, Taiwan, } \\
\text { Colombia }\end{array}$ & $\begin{array}{l}\text { Integration (introduction) of evidence- } \\
\text { based dentistry in the curriculum } \\
\text { (evidence-based dentistry throughout the } \\
\text { six-year period of dentistry education) }\end{array}$ & Vertical & * \\
\hline 17 & Switzerland, Dundee & $\begin{array}{l}\text { Integration of new sciences into } \\
\text { dentistry (addition of new sciences } \\
\text { related to dentistry and teaching them } \\
\text { throughout the six-year period of } \\
\text { dentistry education) }\end{array}$ & Vertical & $*$ \\
\hline 18 & $\begin{array}{c}\text { Colorado, Columbia, } \\
\text { Illinois }\end{array}$ & $\begin{array}{l}\text { Integration (introduction) of the } \\
\text { treatment plan into the dentistry } \\
\text { curriculum (addition and design of the } \\
\text { treatments and integration into the } \\
\text { clinical courses of dentistry) }\end{array}$ & Vertical & $*$ \\
\hline
\end{tabular}

In the third and the latest review of the dental education program in Iran carried out by the Dental Education Review Committee of Shahid Beheshti Dental School in 2000 (approved by the Supreme Council of Medical Planning), emphasis was placed on the training of human resources in the dentistry sector aiming to provide, maintain, and promote oral and dental health in the community, which has not been achieved so far.

Within the past few years, there has been growing protest against the contents of the curriculum of the doctoral program for dentistry. In the viewpoint of managers and policymakers of the education and healthcare system in the dental education sector, the main shortcomings of dental education in Iran include the lack of comprehensiveness and devoting less attention to the preventative aspects of clinical practice in the curriculum, separation of basic sciences education from the clinical courses, insufficient motivation in the learners for continuous studies, and weakness in the training of the individuals who are independent in this sector (20). Therefore, a review of the dental curriculum, which is regarded as an essential component 
of educational development, has been confirmed as a definite necessity (21). Correspondingly, the general doctoral program of dentistry should be a communityoriented program with the following features: -Attention to community needs, health priorities, economic, financial, and human resources, facilities and equipment, technological advances, quantitative and qualitative increase of knowledge and information, and establishment of cultural, health, medical, and educational policies, and teaching methods;

- Considering the healthcare needs of the general population, especially in underprivileged areas and villages, in terms of education;

- Emphasis on the prevention on all the levels;

- Coordination between the educational system and healthcare system;

- Integration of basic sciences and clinical sciences;

- Developing self-education and selfassessment capabilities in graduate students;

- Improvement of communication skills and changing the attitudes and therapeutic approaches $(20,22)$

Through a quick review of the current dental curriculum in Iran, it could be realized that several of the aforementioned principles, which have been confirmed by the World Dental Federation (FDI), are not observed in this curriculum. Meanwhile, reviewing the curriculum every 3-4 years is another requirement considering that the latest revision of the dental curriculum in Iran was performed in 2000.

Since it is not possible to address all the patterns of dental education curriculum in Iranian medical universities, only one example of curriculum integration has been mentioned in the current review based on the previous studies focusing on the current Iranian dentistry curriculum and examination of the current integration methods for the curriculum of reputable international universities. These universities have been considered as a model for the integration of the dentistry curriculum in Iran (23). This pattern has been implemented at the School of Dentistry at Shahid Beheshti University of Medical Sciences (Tehran, Iran) and includes a curriculum that runs over a period of six years in five stages. Each stage with the introduced topics and its detailed description have been shown in Table 3 (24). 
Table 3: Revisions of Dentistry Education Curriculum at Shahid Beheshti University of Medical Sciences, Iran

\begin{tabular}{|c|c|c|}
\hline Stages & Title & Features \\
\hline $1^{\text {st }}$ Stage & $\begin{array}{c}\text { Basic } \\
\text { Medical } \\
\text { Sciences }\end{array}$ & $\begin{array}{l}\text { At this stage, basic sciences and general courses are presented during three } \\
\text { semesters with the following modifications: } \\
\text { 1. Adding courses to build self-centered learning capabilities with the addition of } \\
\text { information technology courses and finding dental evidence. } \\
\text { 2. Horizontal integration of the contents of basic medical sciences in the form of } \\
\text { body systems } \\
\text { 3. Vertical integration of the theoretical contents of traditional courses on internal } \\
\text { diseases and pathology into the contents of the courses on body organs. In this } \\
\text { section, the most common or important diseases are considered from the perspective } \\
\text { of a dentist. } \\
\text { 4. Addition of basic CPR courses } \\
\text { 5. Addition of general communication skills } \\
\text { 6. Addition of early contact with patients }\end{array}$ \\
\hline $2^{\text {nd }}$ Stage & & $\begin{array}{l}\text { This phase, which is intended as a one-semester course, contains courses that } \\
\text { provide students with specific topics on basic dental sciences with the following } \\
\text { modifications: } \\
\text { 1. Vertical integration of histology and pathology in the form of oral } \\
\text { histology/pathology } \\
\text { 2. Vertical integration of embryology with congenital oral diseases as a course of } \\
\text { dentofacial growth and development } \\
\text { 3. Presentation of pharmacology in the integration of oral microbiology and oral } \\
\text { antimicrobial pharmacology } \\
\text { 4. Vertical integration of oral diseases into the mentioned courses } \\
\text { 5. Presentation of new courses (physics of radiology and protection, occlusion and } \\
\text { masticatory system, and local anesthesia and nerve blocks) } \\
\text { 6. Continuous communication skills training in clinical communication skills } \\
\text { training } \\
\text { 7. Continuing to organize the topic of community-based dentistry during this phase } \\
\text { in course of the 'Foundations of Oral Health' } \\
\text { 8. New organization of English language in the curriculum in this phase has been } \\
\text { observed, so that by changing the contents, students could study dentistry references } \\
\text { by the end of the course. } \\
\text { 9. New organization of the topic of research in the curriculum, starting with the } \\
\text { presentation of the research methodology course at this stage. }\end{array}$ \\
\hline
\end{tabular}




\section{Continue of Table 3: Revisions of Dentistry Education Curriculum at Shahid Beheshti University of Medical Sciences, Iran}

Duration of this phase is two years, with the aim of preparing students to assume the responsibility of patient administration as a general dentist with the following modifications:

1. Theoretical and practical integration (pre-clinical and clinical) of clinical courses into specialized departments

2. Integration of courses on dentistry materials in clinical departments

3. Continuing training on evidence-based dental positions in this phase during the two periods of critical appraisal of dental literature and 'Evidence-based Dentistry'

$\begin{array}{cc}3^{\text {rd }} \text { Stage } & \text { Preclinical } \\ & \text { Dental } \\ \text { Sciences }\end{array}$

Sciences
4. Continuing education on emergency medical units in this phase by providing new courses of advanced CPR and medical emergencies

5. Continuing education on community dentistry in the curriculum by providing a new course of 'Preventative Dentistry 1-2' and 'Promoting Individual Oral Health'

6. Promoting student responsibility in patient administration (key role of dentistry assistants for students at this stage)

7. Continuing English language learning to achieve the goals of speaking English as a dentist

8. Continuing the teaching of ethics and professional behaviors as 'Ethical Vignette Case Discussion'

9. Offering selective courses to dentistry students

Duration of this phase is 18 months, with the aim of gaining experience, developing skills, improving decision-making, increasing self-esteem, and completing the development of thoughts through the direct confrontation of the trainees with oral and dental health issues and assigning responsibilities for the oral health of patients with the following features:

1. Providing clinical experiences in general clinics

$4^{\text {th }}$ Stage $\quad \begin{gathered}\text { Dental } \\ \text { Clerkship }\end{gathered}$

2. Training under the supervision of an educational preceptor

3. Teaching based on the tasks of dentists

4. Continuing English language learning at the level of achieving English writing objectives

5. Continuing ethical and professional behavior education as 'Ethical Consultation Sessions'

6. Continuing medical emergency care training as 'Crisis Management'

7. Continuing community education in the curriculum by providing longitudinal courses as ‘Community Oral Health Promotion' and 'System-based Dental Practice' 


\begin{tabular}{|c|c|}
\hline \multicolumn{2}{|c|}{$\begin{array}{l}\text { Continue of Table 3: Revisions of Dentistry Education Curriculum at Shahid Beheshti University of Medical } \\
\text { Sciences, Iran }\end{array}$} \\
\hline \multirow{8}{*}{$\begin{array}{l}\text { Integrated } \\
\text { Dentistry } \\
\text { Internship }\end{array}$} & $\begin{array}{l}\text { This phase is a completely new experience in the dental curriculum based on the } \\
\text { actual goals and commitments of the oral health care system in the community. In } \\
\text { this phase, students have completed the integrated studies of oral and dental clinics, } \\
\text { and while experiencing independent dental practice, provide oral health care to the } \\
\text { community as a general dentist under the following conditions: } \\
\text { 1. First-level providers of oral care services regardless of age and gender of } \\
\text { patients }\end{array}$ \\
\hline & $\begin{array}{l}\text { 2. Effective use of healthcare resources through coordinated care and collaboration } \\
\text { with other healthcare providers of oral health care in the national healthcare system }\end{array}$ \\
\hline & $\begin{array}{l}\text { 3. Provision of individual services by considering the specific circumstances of } \\
\text { patients, their families, and the community }\end{array}$ \\
\hline & $\begin{array}{l}\text { 4. Establishing long-lasting consultation advice through effective communication } \\
\text { between dentists and patients }\end{array}$ \\
\hline & 5. Provision of continuous, long-term care services in accordance with patient needs \\
\hline & 6. Diagnosis and treatment of acute and severe oral diseases \\
\hline & 7. Promotion of health through effective and appropriate interventions \\
\hline & 8. Responsibility for oral and dental health of the community \\
\hline
\end{tabular}

Based on the comprehensive care model provided by the Committee on the Future of Dental Education, every dental student is responsible for the provision of care to address the therapeutic needs of patients, and the training in this regard should not be based on separate, specialized disciplines, so that each dentistry school would have a separate department for general dentistry $(25,26)$. Marquette University has implemented a syllabus entitled the "Comprehensive Patient Care Program", in which the clinical curriculum of the School of Dentistry is based on the 'general practice model'. The philosophy of this model is that a comprehensive, high-quality program operates more successfully in dental care without division into its disciplines or separate specialties (27). This program is patient-oriented and managed by the guidance of general dentists, thereby allowing the integration of behavioral sciences, basic sciences, and clinical sciences into patient care and treatment (28).

The University of Connecticut has presented a unique program on biodontics in the form of 
introducing new biological sciences and research into dentistry. The main purpose of this new curriculum is to exploit new discoveries, such as molecular biology, biotechnology, and informatics, in the educating of dentists so as to provide more efficient services to patients. The program partly includes translational research training and clinical trial programs, which have been designed to integrate basic sciences into clinical applications and new technologies, including probiotics, dental laser, and electronic patient record system. Furthermore, the highest level of the Biodontics Educational Program (BEP) has been provided in a formal apprenticeship course, resulting in an official certificate after two years of training $(27,29)$.

At the University of Texas, the dental curriculum has been reviewed in terms of the use of new sciences on all the levels, and a critical evaluation approach has been applied in this regard. The main achievements of the review of the dental curriculum in this university could be summarized, as follows:

1. Students and professors should experience evidence-based practice;

2. Students and professors should be able to critically evaluate all the educational and therapeutic issues;
3. Strategies for clinical teaching should be followed in education.

In this curriculum, which is known as the CAT, new information has been integrated into the dental curriculum and private practice settings, giving the students an opportunity to become practically acquainted with the form of dentistry that has fundamentally been combined with new sciences and technologies $(3,4,30)$.

According to the examination of the experiences of the world's most reputable universities in this review, the major problems in the dental curriculum include the lack of horizontal and vertical integration, while a notable amount of the repetitive contents taught in various forms in different courses disrupt learning in the students. In this regard, the common solution to this problem proposed by various universities is to determine the core curriculum, so that the dental school could keep up with the original materials that a knowledgeable dentistry graduate should master, while reducing the unnecessary scientific contents in the curriculum. The core/pivotal curriculum should include the knowledge, skills, and professional qualifications essential to the initiation of clinical practice by a graduate dentist in the community. In fact, such a 
curriculum is based on the outcomes expected from a dental faculty, which is of great interest to many dental schools across the world nowadays (31).

Considering that a general dentist should be able to access the required knowledge, skills, and attitudes to provide effective care to patients, integration has been accepted as an important educational strategy in dental education. In fact, integration involves the organization of educational materials in order to establish an interconnection between these materials or integrate the materials that are often taught separately in academic courses or departments. In addition to creating a more understandable meaning of various concepts, integration often increases the efficacy of a system and is regarded as a key influential factor in the provision of effective educational programs.

In the traditional educational system, unnecessary repetitions were common. With the countless teaching approaches in these program, concepts were occasionally incompatible, which caused students to be mentally disturbed. An integrated curriculum increases the effectiveness of the educational system through avoiding unnecessary repetitions and saving time. In addition, integration provides the possibility of allocating educational resources in a more rational way. Through integration, the amount of fragmented knowledge reduces, which in turn significantly increases the possibility of providing a unique conceptual map.

Given the importance of the integration strategy, it has been widely recognized as an outstanding feature of the educational system reform in recent years, and many dental schools have adopted this strategy in their reform plans since the 1990s. Therefore, the desirable status of the dental curriculum could be expected in the horizontal and vertical integration of the curricula. Horizontal integration, which integrates parallel disciplines, has been defined as the integration of basic sciences with each other or integration of clinical sciences with each other in dentistry education. A clear example of horizontal integration is the organization of the contents of basic sciences around the organ system approach, in which the sciences of anatomy, physiology, histology, and cardiovascular system are presented simultaneously and meticulously sequentially, along with its various topics. Currently, horizontal integration is implemented in almost $10 \%$ of the universities in North America, including Pennsylvania, Maryland, 
and Ohio universities, and is considered to be a fundamental measure in the new reform agenda of most of the universities across the world. Another example of horizontal integration is the integration of clinical sciences with each other, which could be easily arranged in an outpatient clinic for health education so as to transfer the concepts of primary care, comprehensive care, and community-based care.

In dental education, vertical integration of the courses that are commonly taught in different disciplines is often defined as the integration of basic and pre-clinical sciences, as well as the integration of pre-clinical and clinical sciences into basic sciences and basic sciences into pre-clinical and clinical sciences. For instance, in the first two and a half years of the curriculum, students are divided into small groups to be introduced to the patients with chronic disorders. Students must apply their knowledge of anatomy, physiology, and biochemistry to solve the problems of these patients. It is notable that both horizontal and the vertical integration may be used in the curriculum.

Modifications and reformation of dental curricula are chiefly based on the introduction of three approaches in the curriculum, including 'education along with research with a dental approach', 'evidence-based dental approach', and 'introduction of new knowledge in the dental approach'. Nevertheless, the centrality of these approaches has not hindered the actions pertaining to specific reforms in the curriculum. Although these cases have not been common, achieving new methods in which new sciences are introduced into dentistry has been further considered in the aforementioned approaches.

Within the past years, scholars have been increasingly focused on research in this regard, even in the colleges with no curriculum modifications, and it seems that they have attempted to introduce new sciences into dentistry in a variety of manners. According to these studies, various types of vertical and horizontal integration have been presented based on integration methods from within and integration from without in dental education curricula of various universities across the world (Table 1). In summary, 40 types of corrective actions were taken in the process of dental curriculum reform throughout the world, which has often involved vertical integration. It is notable that the benefits of vertical integration differ from those in horizontal integration, and the former has been explored more 
frequently in the past two decades.

According to the review of the integrated syllabi in the studied universities in the current research,thebasis for the modifications and reforms in the curricula have been the principles of integrating the dental curriculum, which were introduced in the context of curriculum studies and for application in the universities in Iran, as follows:

Principle 1: Simultaneous Integration at Micro and Macro Levels

Based on this principle, attention must be paid to integrating the curriculum into one material (i.e., interdisciplinary integration) and integration among various materials (i.e., multidisciplinary integration) $(21,32)$.

\section{Principle 2: Variety of Methods and Multidimensionality}

The curriculum integration model should not address integration dogmatically and fanatically. To this end, providing a continuum of integration approaches by curriculum experts (e.g., Jacobs, Fogarty and others) could provide a flexible curriculum in terms of selecting various approaches and improve the efficiency of the curriculum in multiple situations. According to Glorathon, there are no optimal integrated curricula, and different types of curriculum offer different models of success and goal achievement (31).
Principle 3: Balance between Content-based and Process-based Curriculum Integration

The curriculum integration model should lead to the balanced combination of content-based and process-based curriculum. In other words, an integrated curriculum should simultaneously deal with the integration of knowledge and process themes, and its achievement should have such feature in each syllabus, as well as in the curriculum of a specific course or field of study $(28,33,34)$.

Principle 4: Complementariness of Integration from Within and from the Outside

The integration model should be focused on 'integration from within' and 'integration from the outside'. Integration from the outside is defined as the design of a curriculum based on organized contents in an integrated as performed by curriculum planners. Conversely, integration from within pertains to learning activities and is an action taken by students. The theory of integration from within faces serious rivals, which supports integration from the outside. Therefore, this issue cannot be considered unilaterally and could be successful (26).

In order to comply with the fundamental principles of integrated dental curriculum planning and based on the global experiences 
of dental curriculum planning, a framework of the dental curriculum integration model has been developed with three levels (35) and four elements (36). Accordingly, the desirable elements of the dental curriculum have been identified and determined based on the combination of these dimensions. At the three levels of the plan, one curriculum is developed at the level of the scientific field, one curriculum is developed at the level of the field of study, and one curriculum is developed at the theme level $(21,26)$. In this regard, the four curriculum elements include purpose, content, methodology, and evaluation (31). At each level and for each element of the curriculum, it is essential to make decisions, the results of which in each case are considered to be the achievements known as the 'curriculum element'. Table 4 presents a set of the desirable elements of an integrated curriculum in dental education, originating from the cross relationship of curriculum levels-elements. Decision on the content of the elements could be made variably; if the principles of an integrated curriculum are followed, an 'integrated curriculum' could be achieved. These decisions lead to 'curriculum mapping' at the macro level, as well as a 'conceptual map' at the micro level (37-39).
Although interdisciplinary integration is prioritized in the mentioned model, the conventional method is not completely neglected, and the parts that are not categorized as the first format are divided into disciplines and themes, with the preservation of the map of each discipline and its specific identity. As a result, interdisciplinary integration and the required materials could be obtained in various manners. Additionally, each curriculum has specific capabilities and could serve the purpose of other lessons. This theme has been presented in the context of the concept of tasks and secondary function and is used consciously. For instance, the natural capacity of anatomy, physiology, histology, and pathology courses is considered to be the basis of realizing human diseases (30).

\section{Discussion}

This was a new research in Iran aiming to discuss the desired status of dentistry curriculum based on the indigenous needs of the Iranian community and international experiences. According to the literature review of the domestic and international studies in this regard, it seems that no similar studies have been conducted with the same objective, and previous studies have been limited to reviewing the general indices of 
integrated dental curriculum in foreign universities (12-17). Therefore, it is not possible to compare the optimal status of dentistry curriculum in Iran due to demographic and ecological differences with the previous studies.

Based on the studies focusing on the current dental curriculum used in Iran (23) and evaluation of the types of integration in the dental curriculum of credible universities across the world $(14,40)$, the desirable status of the general dental curriculum in Iran requires an integrated curriculum that is implemented in a six-year period in six steps, as follows:

The First Year: Learning Behavioral and Basic Sciences

At this stage, the dental curriculum should encompass communicational skills, acquiring self-centered and lifelong learning abilities, study skills, research in dental resources, early exposure to diseases, English language teaching, professional ethics in dentistry, informatics and information resources, and evidence-based dentistry, which are a collection of courses that are presented in the first year of dentistry education. These items are in line with the items provided in the dental curriculum of international universities $(12,16,41)$.

\section{The Second Year: Basic Medical Sciences}

At this stage, the dental curriculum should encompass the horizontal integration of the contents of basic medical sciences in the form of body organs, vertical integration of the theoretical contents of the conventional courses regarding internal diseases, and pathology within the context of the courses focusing on the body organs. In this section, the most common or significant diseases from the perspective of a dentist are incorporated into the curriculum. Furthermore, the addition of the basics of resuscitation and medical and dental emergency courses, early encounters with patients, and dental genetic tests are presented in the second year of education. These items are in line with the items in the dental curriculum of international universities $(13,42)$.

\section{The Third Year: Basic Dental Sciences}

This stage requires students to become acquainted with the special topics of basic sciences in dentistry, dental research, and introduction of new sciences in dentistry, which are part of dentistry education in the third year. These items are in line with the items in the dental curriculum of the universities in the United States $(14,40)$.

\section{The Fourth Year: Pre-clinical Dentistry}

This stage aims to prepare the student for 
undertaking the responsibility of patient management as a general dentist. The key features of this phase include presenting theoretical and practical courses (phantom and clinical) as integrated into the clinical departments, which are viewed as education in the relevant specialized departments. Moreover, by defining the new role of dental assistants for students in this phase, students could be more involved in patient management than in the traditional curriculum. As such, they are encouraged to write scientific papers and evaluate and criticize scientific papers for familiarization and research experience. These items are in line with the items in the dental curriculum of American and European universities (12, 43).

\section{The Fifth Year: Dentistry Internship}

This aim of this stage is to acquire experience, develop skills, improve decision-making, increase reliance on self-esteem, and complete the development of thoughts through the direct confrontation of student with oral and dental health issues in order to assign oral and dental health responsibilities to patients. Furthermore, this stage involves applying an evidence-based dental approach. These items are in line with the items in the dental curriculum of American and European universities $(40,44)$.

\section{The Sixth Year: Internship in the Dentistry Community}

This stage represents an entirely new experience in dentistry curriculum, which is based on the actual goals and commitments of the oral health system in the community. In this phase, students complete the courses of integrated care in the oral and dental health clinics affiliated to the university, and while experiencing independent medical practice, undertake public oral health care as a general dentist under the following conditions and supervision of a consultant professor:

1. Provision of first-line oral care services regardless of the age and gender of patients;

2. Effective use of healthcare resources through coordinated care and in collaboration with the other members of the oral healthcare group in the national healthcare and treatment system;

3. Provision of individual services by considering the particular circumstances of the patients, their families, and the community;

4. Establishment of long-lasting counseling relationships through effective communication between the patients and physicians;

5. Provision of continuous, long-term care services in accordance with the 
individual needs of the patients;

6. Diagnosis and treatment of acute and chronic oral and dental diseases;

7. Promotion of health through effective and appropriate interventions.

The internship practices presented in the preferred dental curriculum in Iran are partly in line with the internship approach adopted at Harvard School of Dentistry (12), which requires students to complete a three-month, out-of-campus course, thereby preparing a final report of their research project.

Considering the dental curriculum based on world-class dental standards presented at the most prestigious universities in the world (1217, 40-44), it could be concluded that the integrated patterns of dental curriculum are classified into two main categories, including integration into some curriculum sections (partialintegration), and using the conventional curriculum with newly added modern subjects. On the other hand, some other points are particularly taken into account in international dentistry schools across the world in this regard, and in order to keep up, Iran has to consider the following points in designing the curriculum of general dental courses basedontheprinciplesoflocalization:

1. Developing self-centered learning and lifelong learning skills;
2. Emphasizing on diminishing the volume of pure information in the curriculum; 3. Explaining the core and optional sections in the curriculum;

4. Providing different forms of integrating basic and clinical knowledge;

5. Development of content domains in the following sections:

- $\quad$ Evidence-based dentistry;

- Information technology;

- Communication skills;

- Medical ethics and professional behaviors;

- Prevention and promotion of health concepts

\section{Conclusion}

According to the results, the optimal condition of general dentistry curriculum in Iran involves an integrated program defined in a six-year period. The benefits of an integrated curriculum are remarkable in the long run (six years) in dentistry, resulting in the enhanced motivation of the students for learning and positively influencing lifelong learning and applying the principles and methods learned by the students. Since the implementation of any integration programs requires the cooperation of the experts in charge of implementation, the final 
implementation of any curriculum is subject to the familiarization and agreement of the beneficiaries. Therefore, it is suggested that the desirable status of the dental curriculum be promoted in dentistry departments by holding related workshops. The limitations of the present study could be attributed to the absence of similar foreign and domestic studies in this regard for comparison purposes.

\section{Acknowledgement}

We thank Dr. Shahram Yazdani for assistance with methodology, and Dr. Aliakbar Haghdoust for comments that greatly improved the manuscript. We would also like to show our gratitude to the Secretariat of Technical and Dentistry Training Council which supported us during this research.

\section{References}

1- Guven Y. Scientific basis of dentistry. J Istanb Univ Fac Dent. 2017; 51(3): 64-71.

2- Koole S, Van Den Brulle S, Christiaens V, Jacquet W, Cosyn J, De Bruyn H. Competence profiles in undergraduate dental education: a comparison between theory and reality. $B M C$ Oral Health. 2017; 17(1):109-116.

3- Abbott D. Development and presentation of the interdisciplinary course petroleum project evaluation: integrating entrepreneurial and business concepts into a petroleum engineering curriculum. In Proceedings of the 2006 ASEE Annual Conference \& Exposition, 2006.

4- Akerson VL. Using action research projects to help preservice elementary teachers effectively use interdisciplinary language arts and science instruction. In V. L. Akerson (Ed.), Interdisciplinary language arts and science instruction in elementary classrooms: Applying research to practice (pp. 279-293). Mahwah, NJ: Lawrence Erlbaum Associates; 2008.

5- Bazargan A. An introduction to qualitative and mixed research methods. Tehran: Didar Pub; 2008. [Persian]

6- Kassebaum DK, Tedesco LA. The $21^{\text {st }}$-century dental curriculum: A framework for understanding current models. J Dent Educ. 2017; 81(8): 13-21.

7- Komenda M, Víta M, Vaitsis C, Schwarz D, Pokorná A, Zary N, Dušek L. Curriculum mapping with academic analytics in medical and healthcare education. PloS One. 2015; 10(12):118.

8- Abbott Ch. ICT: Changing education. Psychology Press; 2003.

9- Lee SM, Ahn SY, Won YS, Kim CH. Development of integrated basic dental hygiene curriculum. Journal of Korean society of Dental Hygiene (JKSDH). 2016; 16(2):165-72.

10- Marshall C, Rossman GB. Designing qualitative research. Sage publications; 2014.

11- Yamani N, Shater Jalali M. Curriculum Integration, with Emphasis on Integration in Medical Education. Iran J Med Educ. 2012; 11(9):1202-13. [Persian]

12- Harvard School of Dental Medicine [Cited 2016 June 10]. Available from: https://hsdm.harvard.edu/

13- Department of Dentistry - University of Virginia School of Medicine [Cited 2017 April 19]. Available from: https://med.virginia.edu/dentistry/ 
14- School of Dentistry; Marquette University [Cited 2017 May 15]. Available from: http://www.marquette.edu/dentistry/

15- Baylor University [Cited 2017 June 15]. Available from: https://www.baylor.edu/

16- Dental School - Boston University [Cited 2017 May 20]. Available from: http://www.bu.edu/dental/

17- Columbia University College of Dental Medicine [Cited 2017 April 19]. Available from: https://www.dental.columbia.edu/

18 Lake K. Integrated curriculum. School improvement research series. 1994; 16. Available from:

https://educationnorthwest.org/sites/default/files/i ntegrated-curriculum.pdf

19- Plasschaert AJ, Lindh C, McLoughlin J, Manogue M, Murtomaa H, Nattestad A, Sanz M. Curriculum structure and the European credit transfer system for European dental schools: part I. Eur J Dent Educ. 2006;10(3):123-30.

20- Johnson CJ. Perceptions of pre-doctoral and dental hygiene students regarding intraprofessional education. A Thesis in Dental Hygiene, Dental Hygiene in the Graduate School of the Ohio State University; 2017.

21- Bassir SH, Sadr-Eshkevari P, Amirikhorheh S, Karimbux NY. Problem-based learning in dental education: a systematic review of the literature. J Dent Educ. 2014; 78(1): 98-109. [Persian]

22- Taheri JB, Jafari S, Farzanegan A, Norouzi A. Assessing the knowledge and attitude about hepatitis $\mathrm{C}$ among dental students in Tehran, Iran in 2014-2015. Journal of Health Policy and Sustainable Health (JHPSH). 2015; 2(2): 195-199.

23- Yazdani Sh, Hosseini F. The Dentistry

Curriculum Revision Plan; 2008. [Persian].

24- Shahid Beheshti University of Medical Sciences and Health Services [Cited 12 April
2018]. Available from: URL: http://www.sbmu.ac.ir/index.jsp?fkeyid=\&siteid= $\underline{19 \& \text { pageid }=17875}$

25- Elliott J. The teacher's role in curriculum development: An unresolved issue in English attempts at curriculum reform. Curr Stud. 1994; 2(1): 43-69.

26- Plasschaert AJ, Holbrook WP, Delap E, Martinez C, Walmsley AD. Profile and competences for the European dentist. Eur J Dent Educ. 2005; 9(3): 98-107.

27- Kalkwarf KL, Haden NK, Valachovic RW. ADEA commission on change and innovation in dental education. $J$ Dent Educ. 2005; 69(10):1085-7.

28- Croft P, Altman DG, Deeks JJ, Dunn KM, Hay AD, Hemingway $H$, LeResche L, Peat G, Perel P, Petersen SE, Riley RD. The science of clinical practice: disease diagnosis or patient prognosis? Evidence about "what is likely to happen" should shape clinical practice. BMC Med. 2015; 13(1): 20-27.

29- Kolahi J. Dental science and technology parks: Rethinking university-industry connections. Dent Hypotheses. 2015; 6(2):40-43.

30- Aboelela SW, Larson E, Bakken S, Carrasquillo O, Formicola A, Glied SA, Haas J, Gebbie KM. Defining interdisciplinary research: Conclusions from a critical review of the literature. Health services research (HSR). 2007; 42(1p1):329-46.

31- Brauer DG, Ferguson KJ. The integrated curriculum in medical education: AMEE Guide No. 96. Med Teach. 2015; 37(4): 312-22.

32- Neary M. Curriculum studies in postcompulsory and adult education: a study guide for teachers and student teachers. Nelson Thornes; 2002.

33- American Dental Association. Accreditation Standards for Dental Education Programs. Commission on Dental Accreditation; Available from: 2016. 
http://www.ada.org/ /media/CODA/Files/predoc. $\underline{\operatorname{ashx}}$

34- Komabayashi T, Raghuraman K, Raghuraman R, Toda S, Kawamura M, Levine SM, Bird WF. Dental education in India and Japan: implications for US dental programs for foreign-trained dentists. J Dent Educ. 2005; 69(4): 461-9.

35- Field JC, Cowpe JG, Walmsley AD. The graduating European dentist: a new undergraduate curriculum framework. Eur J Dent Educ. 2017; 21(S1): 2-10.

36- West E, Loftin CT, Snyder CL. Curriculum design. Position Paper. 2017; 6.

37- Wang CL. Mapping or tracing? Rethinking curriculum mapping in higher education. Studies in Higher Education. 2015; 40(9):1550-9.

38- Jacobs HH. Interdisciplinary curriculum: Design and implementation. Association for Supervision and Curriculum Development, 1250 N. Pitt Street, Alexandria, VA 22314; 1989.

39- Beane JA. Curriculum integration: Designing the core of democratic education. Teachers College Press; 2016.
40- University of Connecticut School of Dental Medicine [Cited 2017 May 8]. Available from: https://dentalmedicine.uconn.edu/

41 - Faculty of Dentistry, University of Toronto [Cited2017April12]. Available from: https://www.dentistry.utoronto.ca/

42- School of Dentistry - University of Louisville [Cited 2017 June 15]. Available from: http://louisville.edu/dentistry/

43- London School of Medicine and Dentistry; University of Cambridge [Cited 2017 April 18]. Available from: https://www.cam.ac.uk/externalaffiliations/london-school-of-medicine-anddentistry

44- Academic Center for Dentistry Amsterdam; University of Amsterdam [Cited 2017 May 3]. Available from: 